\title{
The Risk of Renal Stone Formation during and after Long Duration Space Flight
}

\author{
Peggy A. Whitson ${ }^{a}$ Robert A. Pietrzyk ${ }^{b}$ Boris V. Morukov ${ }^{c}$ \\ Clarence F. Sams ${ }^{a}$ \\ aNASA/Johnson Space Center and bWyle Life Sciences, Houston, Tex., USA c Institute for Biomedical Problems, \\ Moscow, Russia
}

Key Words

Renal stone $\cdot$ Space flight · Aerospace medicine

\begin{abstract}
Background: The formation of a renal stone during space flight may have serious negative effects on the health of the crewmember and the success of the mission. Urinary biochemical factors and the influence of dietary factors associated with renal stone development were assessed during long duration Mir Space Station missions. Methods: Twenty-four-hour urine samples were collected prior to, during and following long duration space flight. The relative urinary supersaturation of calcium oxalate, calcium phosphate (brushite), sodium urate, struvite and uric acid were determined. Results: Changes in the urinary biochemistry of crewmembers during long duration spaceflight demonstrated increases in the supersaturation of the stone-forming salts. In-flight hypercalciuria was evident in a number of individual crewmembers and 24-hour dietary fluid intake and urine volume were significantly lower. During flight, there was a significant increase in brushite supersaturation. Conclusions: These data suggest acute effects of space flight and postflight changes in the urinary biochemistry favoring increased crystallization in the urine. The effects of dietary intake,
\end{abstract}

especially fluid intake, may have a significant impact on the potential for renal stone formation. Efforts are now underway to assess the efficacy of a countermeasure to mitigate the increased risk.

Copyright $\odot 2001$ S. Karger AG, Basel

\section{Introduction}

The health and safety of the crewmembers is a prime focus for the National Aeronautics and Space Administration (NASA) and the Russian space program. It is now well established that humans can live, work, and function effectively in microgravity. However, human exposure to the weightless environment produces many changes, both acute and chronic, to all physiologic systems of the human body [1-2]. Changes to the cardiovascular, skeletal, muscular, and fluid-regulating systems are well-documented both during flight and upon return to Earth [3-5].

Recent evidence from NASA and the Russian space program has shown that humans exposed to the microgravity environment of space have a greater risk for developing renal stones [6-8]. The majority of renal stones formed here on Earth are composed of calcium oxalate or a mixture of calcium oxalate and calcium phosphate. Biochemical changes in the urinary chemistry lead to the pre-

\section{KARGER \\ Fax +41613061234 E-Mail karger@karger.ch www. karger.com

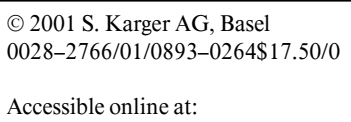

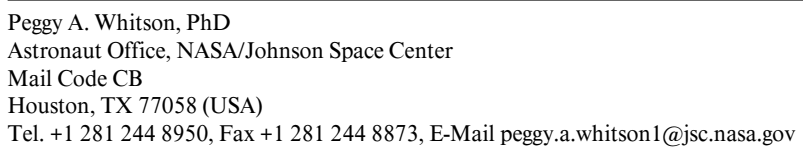


cipitation of urinary salts and subsequent aggregation and growth into renal stones. Stone growth then depends on the urinary chemical environment, the presence of stone inhibitors, the volume of the urine and any underlying medical condition.

During space flight, the increased risk begins early during the mission and continues after landing. This increased risk occurs in most crewmembers during both short (less than 21 days) duration $[6,8]$ or long duration (greater than 100 days) missions [7, this paper]. Despite a screening program for potential risk factors prior to flight, ten renal stone episodes among crewmembers have been documented in the U.S. space program and the Russian space program has reported one in-flight renal stone occurrence. Obviously, the development of a renal stone during space flight would have serious consequences both for the health of the crewmember and the success of the mission.

This investigation provides new information about the risk of renal stone formation in crewmembers during long duration space flight aboard the Mir Space Station. The objectives were to determine the biochemical changes in the urine of these crewmembers, evaluate the potential influence of dietary factors and as a result of this study, propose possible countermeasures to minimize the risk.

\section{Methods}

\section{Subjects}

This study was approved by the Johnson Space Center Human Research Policies and Procedures Committee and the Russian Space Agency. All subjects gave informed consent before participating. Eleven astronauts and cosmonauts (mean age, 44.5 years, range 32 54) who flew on the Mir space station for missions ranging from 129 to 208 days provided the samples in this study.

\section{Urine Collection}

Each crewmember collected urine during a minimum of two 24hour periods before launch. During flight, void-by-void urine samples were collected early (flight days $<30$ ) and late during the flight (flight days $>60$ ) from the eleven long duration cosmonauts and astronauts. After landing, void by void 24-hour urine was collected on landing day and at various times through 16 days postflight.

Urinary factors associated with renal stone formation were analyzed by using the methods described in detail elsewhere [6]. Briefly, preflight and postflight samples were collected into containers and stored at approximately $4{ }^{\circ} \mathrm{C}$. At the end of each period, the contents were mixed and transferred into a graduated cylinder for total volume and $\mathrm{pH}$ measurements. A $10-\mathrm{ml}$ aliquot was removed for biochemical analyses. A second 10-ml aliquot was acidified with $6 \mathrm{M}$ hydrochloric acid for the analysis of citrate, oxalate and sulfate. Two additional aliquots were removed and thymol and thimerosal were added to serve as controls for the room temperature storage for the in-flight samples.
During flight, crewmembers collected urine in specially designed collection devices containing $1.0 \mathrm{ml}$ of $2.5 \mathrm{M}$ lithium chloride as a volume marker. After mixing the contents well, crewmembers withdrew $2 \times \sim 7-\mathrm{ml}$ aliquots, placing them into tubes containing $0.05 \%$ thymol or $0.1 \%$ thimerosal, and stored them at ambient temperature for the remainder of the flight. Studies in our laboratory and others [9] have shown that thymol and thimerosal are effective for extended periods of time for preserving the renal stone risk factors presented in this study. Preflight and postflight urine collection and dietary monitoring were performed at the Johnson Space Center (Houston, TX) and the Gagarin Cosmonaut Training Center (Star City, Russia). Sample analysis and renal stone risk assessment were performed at the Johnson Space Center Biochemistry and Clinical Laboratories. Prior to analysis, 24-hour urine pools were constructed. With the lithium concentration, it was possible to determine the percentage of each in-flight urine void that contributed to the 24-hour urinary output and reconstruct a pool representative of the 24-hour period. Since the study involved in-flight urine collections chemically preserved and stored at room temperature, the determination of urinary ammonia levels was not possible. The authors used a mean value of $40.0 \mathrm{mEq} /$ day based on a healthy population of non-stone-forming subjects on a normal diet for the determination of the relative struvite saturation.

\section{Urinary Supersaturation}

The relative urinary supersaturations were determined using the method of Finlayson [10]. These unitless ratios were determined from the activity product of the various concentrations of the urinary chemical composition and represent the saturation of the stoneforming salts and the concentration of the undissociated uric acid. The supersaturation data are expressed relative to the values from normal non-stone-forming subjects and indicate the state of urinary supersaturation, a fundamental requirement for stone formation. Urinary supersaturation values $>2$ indicate an increased risk for calcium oxalate, brushite, sodium urate and uric acid stone formation. Values $>75$ reflect an increased risk for struvite stones.

\section{Dietary Monitoring}

Before and after flight, crewmembers maintained daily handwritten logs of food and fluid consumption for the $24 \mathrm{~h}$ prior to and the $24 \mathrm{~h}$ during each urine-collection period. During flight, consumption of food and fluid was monitored according to the same schedule, but subjects used an automated bar-code scanning system in which each individually packaged food item was labeled.

The in-flight diet was designed to meet the nutritional requirements for International Space Station missions as established by NASA and the Russian Space Agency [11]. Neither diet nor activity levels were restricted during any of the sampling periods. In-flight consumption data were stored in the barcode reader and downloaded after landing. Nutrient content of the preflight and postflight foods was calculated with the Minnesota Nutrition Data System (NDS) software program (versions 2.7, 2.8 and 2.91), developed by the Nutrition Coordinating Center (NCC), University of Minnesota, Minneapolis, Minn. (Food Database versions 8A, 10A, and 12, Nutrient Database versions 23, 25, and 27). Nutrient content of the in-flight foods were calculated from food chemical data generated by the Johnson Space Center Water and Food Analytical Laboratory. Net alkali absorption (NAE, $\mathrm{mEq} / 24 \mathrm{~h}$ ) was derived from urinary values as previously described $[8,12]$. 
Table 1. Urinary biochemistry of Mir crewmembers before, during and following long duration space flight

\begin{tabular}{|c|c|c|c|c|c|c|}
\hline & Preflight & $\begin{array}{l}\text { Early in-flight } \\
\text { (< flight day } 30)\end{array}$ & $\begin{array}{l}\text { Late in-flight } \\
(<\text { flight day } 60)\end{array}$ & $\mathrm{R}+0-3$ days & $\mathrm{R}+5-10$ days & $R+12+$ days \\
\hline Urine vol, $1 /$ day & $1.344(0.13)$ & $0.914(0.12)^{*}$ & $0.967(0.08)^{*}$ & $1.083(0.14)$ & $1.34(0.19)$ & $1.158(0.13)$ \\
\hline $\mathrm{pH}$ & $5.92(0.10)$ & $6.14(0.10)$ & $5.91(0.11)$ & $6.03(0.12)$ & $6.21(0.15)$ & $5.95(0.12)$ \\
\hline Calcium, mg/day & $232.9(19.6)$ & $239.3(29.3)$ & $239.9(30.9)$ & $232.1(25.5)$ & $204.1(16.5)$ & $154.0(14.2)^{*}$ \\
\hline Phosphate, mg/day & $976.3(54.7)$ & $873.4(102.9)$ & $916.6(109.6)$ & $646.2(78.7)^{*}$ & $830.7(45.9)$ & $771.4(84.0)$ \\
\hline Oxalate, $\mathrm{mg} / \mathrm{day}$ & $38.5(2.9)$ & $29.2(10.1)$ & $23.8(2.9)^{*}$ & $32.2(3.2)$ & $41.2(3.0)$ & $32.9(3.2)$ \\
\hline Sodium, mg/day & $4,140.3(357.6)$ & $2,839.3(491.5)$ & $3,112.0(332.0)$ & 2,876.9 (291.5) & $4,385.3(498.7)$ & $3,252.0(328.9)$ \\
\hline Potassium, mg/day & $2,945.1(182.4)$ & $2,515.6(251.4)$ & $2,916.7(196.3)$ & $2,427.9(341.0)$ & $3,484.2(527.9)$ & $2,610.4(341.5)$ \\
\hline Magnesium, mg/day & $108.0(7.8)$ & $112.6(15.2)$ & $103.2(11.4)$ & $67.7(7.7)^{*}$ & $86.0(10.5)$ & $75.9(15.4)^{*}$ \\
\hline Citrate, $\mathrm{mg} /$ day & $607.4(59.4)$ & $710.8(88.1)$ & $575.0(59.5)$ & $612.8(65.0)$ & $771.1(85.5)$ & $700.2(113.4)$ \\
\hline Sulfate, $\mathrm{mmol} / \mathrm{day}$ & $22.5(1.15)$ & $19.4(3.32)$ & $21.8(1.9)$ & $20.5(2.3)$ & $17.6(1.3)$ & $14.0(2.1)^{*}$ \\
\hline Uric acid, mg/day & $550.7(52.1)$ & $361.7(67.6)$ & $421.5(52.0)$ & $530.3(38.2)$ & $689.7(59.4)$ & $462.5(44.7)$ \\
\hline Creatinine, $\mathrm{mg} /$ day & $1,658.7(66.2)$ & $1,569.9(154.9)$ & $1,592.6(92.0)$ & $1,668.2(86.2)$ & $1,688.9(86.2)$ & $1,517.3(164.0)$ \\
\hline \multicolumn{7}{|c|}{ Calculated relative supersaturation } \\
\hline Calcium oxalate & $2.66(0.22)$ & $3.57(1.29)$ & $2.59(0.38)$ & $3.67(0.33)$ & $2.76(0.38)$ & $2.26(0.31)$ \\
\hline Brushite & $2.16(0.24)$ & $4.63(0.75)^{*}$ & $3.29(0.41)$ & $2.62(0.47)$ & $2.17(0.31)$ & $1.54(0.28)$ \\
\hline Sodium urate & $4.06(0.55)$ & $3.59(0.62)$ & $3.83(0.53)$ & $4.93(0.96)$ & $6.57(1.02)$ & $3.56(0.72)$ \\
\hline Struvite & $1.50(0.25)$ & $5.54(1.51)$ & $3.31(1.23)$ & $2.90(1.20)$ & $4.10(2.52)$ & $1.49(0.70)$ \\
\hline Uric acid saturation & $2.39(0.37)$ & $1.32(0.26)$ & $2.12(0.40)$ & $2.96(0.52)$ & $2.38(0.64)$ & $2.03(0.37)$ \\
\hline
\end{tabular}

Data represent the means $( \pm \mathrm{SEM})$ before, during and after space flight. $\mathrm{n}=11 ; * \mathrm{p}<0.05$. R+ $=$ days from landing.

Table 2. Dietary data of Mir crewmembers before, during and following long duration space flight

\begin{tabular}{lccccrr}
\hline & Preflight & $\begin{array}{l}\text { Early in-flight } \\
(<\text { flight day 30) }\end{array}$ & $\begin{array}{l}\text { Late in-flight } \\
(<\text { flight day 60) }\end{array}$ & R+0-3 days & R+5-10 days & R+12+ days \\
\hline Energy intake, kcal & $2,825.9(213.1)$ & $1,755.7(356.9)$ & $2,317.4(149.4)$ & $2,706.8(299.4)$ & $2,960.7(201.7)$ & $2,944.0(268.8)$ \\
Fluid intake, ml/day & $2,459.6(183.3)$ & $1,353.6(283.3)^{*}$ & $1,730.1(177.0)$ & $2,432.6(340.5)$ & $2,547.9(255.3)$ & $2,084.5(225.1)$ \\
Protein intake, gm/day & $108.6(7.7)$ & $71.0(14.6)$ & $105.3(10.4)$ & $95.6(10.1)$ & $106.1(9.9)$ & $108.9(12.2)$ \\
Calcium, g/day & $983.6(77.2)$ & $636.3(111.7)$ & $804.3(94.5)$ & $955.7(215.4)$ & $1,171.5(206.5)$ & $998.2(232.9)$ \\
Phosphorus, g/day & $1,573.5(108.2)$ & $1,057.3(202.6)$ & $1,532.4(90.2)$ & $1,475.2(218.1)$ & $1,562.0(155.2)$ & $1,551.8(186.8)$ \\
Oxalate, mg/day & $544.3(68.0)$ & $116.3(28.6)^{*}$ & $234.1(63.8)^{*}$ & $592.5(99.6)$ & $791.9(112.1)$ & $532.0(113.8)$ \\
Sodium, mEq/day & $4,452.4(315.7)$ & $3,350.8(594.0)$ & $4,148.3(365.6)$ & $4,048.8(558.1)$ & $4,136.0(444.2)$ & $4,772.0(413.7)$ \\
Potassium, mEq/day & $4,256.9(319.8)$ & $2,512.1(562.9)^{*}$ & $3,346.3(251.8)$ & $3,707.4(373.7)$ & $4,638.5(457.6)$ & $3,804.9(391.3)$ \\
Magnesium, mg/day & $380.5(27.8)$ & $266.3(48.4)$ & $324.1(26.8)$ & $329.2(26.0)$ & $416.3(41.8)$ & $435.6(56.4)$ \\
\hline
\end{tabular}

Data represent the means $\left( \pm\right.$ SEM) before, during and after space flight. $\mathrm{n}=11 ;{ }^{*} \mathrm{p}<0.05 . \mathrm{R}+=$ days from landing.

Fluid intake was ad lib during all sampling periods. However, all crewmembers were requested to consume the equivalent of normal saline (in the form of salt tablets ingested with approx. 1 liter water) about $90 \mathrm{~min}$ before landing as part of an established protocol to minimize orthostatic intolerance upon re-exposure to gravity.

\section{Statistics}

Statistical tests included paired t test, Pearson product moment correlation and one-way repeated analysis of variance, with significance located by Dunnett's post hoc test. Statistical significance was accepted at the 0.05 level. Statistical analyses were completed using SigmaStat statistical software (SPSS Inc, Chicago, Ill.). All data are reported as means \pm SEM.

\section{Results}

The urinary biochemistry data from these 11 crewmembers are shown in table 1 . Crewmembers involved in this part of the study were a combination of astronauts $(n=3)$ and cosmonauts $(n=8)$ living and working on the Mir space station. All missions were greater than 100 days in length.

There was a significant $47 \%$ decrease in urine volume early during the missions (< flight day 30) and a 39\% lower urine output late in the mission ( $>$ mission day 60 ). As a result of the large individual subject range and limited 
subject number, there was no statistical increase in urinary calcium levels during or after long duration space flight. Urinary calcium levels during the preflight period range from 159 to $316 \mathrm{mg} /$ day, and during flight the range was $129-435 \mathrm{mg} /$ day. During flight, 7 of the 11 crewmembers demonstrated higher in-flight urinary calcium values as compared to their respective preflight levels and 5 of these 11 crewmembers exhibited clinical hypercalciuria (calcium $>250 \mathrm{mg} /$ day). Urinary calcium was significantly lower during the second week after return to Earth.

Preflight calcium oxalate and calcium phosphate (brushite) levels were above the normal non-stone-forming range $(>2.0)$, representing a greater risk than a normal non-stone-forming population. The average $\mathrm{CaOx}$ risk was further increased during the early in-flight period, although not significantly. Calcium phosphate (brushite) risk for these long duration crewmembers was significantly increased early in-flight.

Dietary factors of the Mir crewmembers are shown in table 2. The diets of these crewmembers were assessed during the 24-hour prior to and during the 24-hour urine collection during all phases of the mission. Energy intake (kcal/day), while not statistically significant, was 38\% less during the early in-flight period and remained lower than preflight levels throughout the flight. Average fluid intake was significantly less $(81 \%)$ early during the mission ( $<$ flight day 30) while no significant changes were noted later during or after flight. Dietary potassium ingestion was reduced early in-flight and oxalate intake was significantly less throughout the mission. All other dietary factors, while not statistically significant, were less than preflight values, corresponding to the overall lower energy intake.

Urinary citrate, a potent inhibitor of calcium-containing stone formation, was significantly lower following short duration Shuttle flights $[6,8]$. No change in citrate level was seen following long duration missions. Recent evidence from this laboratory [8] and others [13] have demonstrated a positive correlation between net alkali absorption (NAE) and citrate excretion during Shuttle flights and in control subjects, respectively. Analysis of the data from this study found a significant correlation between urinary citrate excretion and net alkali absorption $(\mathrm{r}=0.226, \mathrm{p}<0.05)$. Additionally, urine volume was significantly correlated to net alkali absorption $(r=0.307$, $\mathrm{p}<0.05$ ).

We separately evaluated 2 additional crewmembers who increased their in-flight hydration. This renal stone countermeasure to minimize the risk of renal stone formation involved an increased fluid intake to ensure that

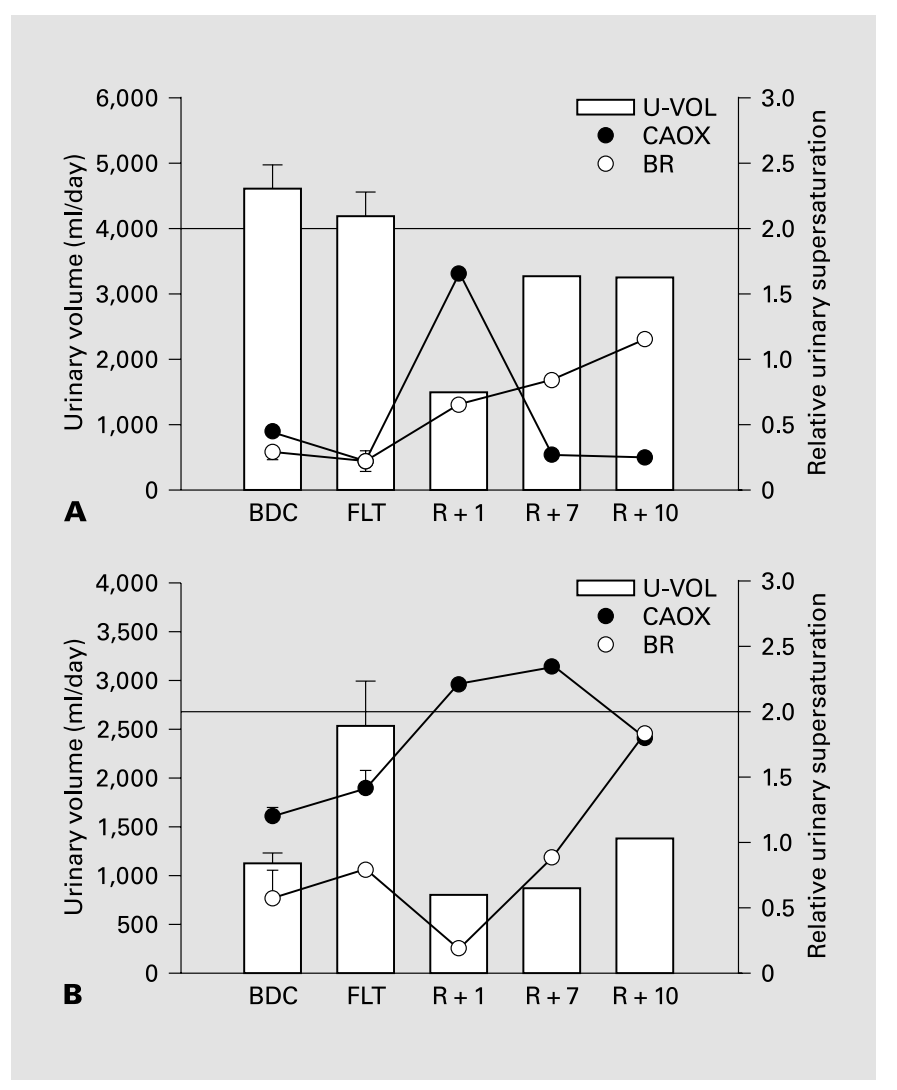

Fig. 1. Direct effect of urine volume on urinary supersaturation. A Data from one crewmember who maintained a high urinary output prior to and during space flight. The risk of calcium stone formation was minimal $(<2.0$ relative urinary supersaturation index $)$ in this subject. B A second crewmember who increased daily urine during space flight and maintained a low risk for calcium stone formation during flight. Postflight, this crewmember demonstrated a low urine volume resulting in an increased risk for calcium stone formation ( $>2.0$ relative urinary supersaturation index). Open bars represent the daily urine volume, $\mathrm{CAOX}=$ calcium oxalate, $\mathrm{BR}=$ brushite or calcium phosphate.

daily urine volume exceeded 2 liters. One subject demonstrated a high averaged preflight daily urine output of greater than $4 \mathrm{l} /$ day during four preflight sessions. This crewmember exhibited a very low risk of either calcium oxalate or brushite (calcium phosphate) stone formation (fig. 1A). The high urinary volume continued during flight, averaging $>4$ 1/day during 3 in-flight collections, and as a result, the crewmember maintained a very low relative urinary supersaturation for calcium-containing stones. A second crewmember had a preflight urine volume during five preflight sessions that averaged $1.357 \pm$ 0.11 1/day. Both $\mathrm{CaOx}$ and brushite supersaturation levels were in the low risk range. During flight, this crewmember 
increased fluid intake, thereby increasing 24-hour urinary volume to an average of $2.53 \pm 0.47 \mathrm{l}$ /day during three in-flight collections. As a result of this greater urinary output, the relative supersaturation of $\mathrm{CaOx}$ and brushite remained in the low-risk range despite an average 35\% increase in urinary calcium during the flight. However, on landing day $(\mathrm{R}+0)$ urine volume was only $0.81 \mathrm{l} /$ day and $0.87 \mathrm{l} /$ day 1 week after landing $(\mathrm{R}+7)$ creating a urinary environment that was supersaturated with the calcium salts and increasing the risk of calcium stone formation after space flight (fig. 1B).

\section{Discussion}

This investigation examined the effects of long duration space flight on the potential for renal stone development. The urinary biochemistry is affected by the human physiological responses to microgravity, influenced by diet and subject to individual response to these stresses placed on the human body. From the data presented here, it appears that there are acute effects of space flight and the return to Earth on the urinary biochemistry that favor increased crystallization in the urine. Changes previously observed during short duration Shuttle flights included a rapid increase in the supersaturation of the stone-forming salts in the urine early during the flight that continued through landing day. However, the stone forming potential in the urine was different during and after space flight. During flight, an increased risk occurred for both calcium oxalate and calcium phosphate stones while immediately after flight the risk was greatest for calcium oxalate and uric acid stone development $[6,8]$. We postulated that the differences observed were related to the initial physiological responses to microgravity and then re-adaption to a $1 \mathrm{~g}$ environment.

Data from these long duration missions suggest a similar trend with respect to renal stone risk. Increased risk for calcium phosphate stone formation occurred early inflight. Although $\mathrm{CaOx}$ stone risk was also increased, the change was not significant in this study. These data suggest that the early phase ( $<30$ days) of space flight may generate conditions in which the risk of stone formation is greater than during the later phases of the mission. These data are consistent with the short duration Shuttle data in which both calcium oxalate and calcium phosphate risk increased during short duration space flights $[6,8]$.

There were fewer significant changes in the urinary electrolytes following long duration missions compared to the Shuttle crewmembers $[6,8]$. Contributing factors to this difference between short and long duration flights may be a differential physiological adaption or varying dietary habits among the long duration international crewmembers. Shuttle and Skylab crewmembers have previously demonstrated a significant increase in urinary calcium on landing day; [1, 6-8, 14, 15] however, our data for these long-duration crewmembers did not. This discrepancy may be attributed to the large individual urinary calcium variation between subjects in our study. However, we observed a greater risk in calcium phosphate stone-forming potential during the early phase of long duration space flight.

In the absence of other medical conditions that may predispose to stone formation, urine volume may be the fundamental aspect in an individual developing renal stones. Renal stone risk assessment is performed on all Shuttle crewmembers prior to and following all space flights. The results of these assessments have proven very beneficial in alerting crewmembers to the value of increasing fluid intake to produce greater urine volumes. Previous data $[6,8]$ from this laboratory have demonstrated that early in the Shuttle program, the urine volume of most crewmembers was significantly lower on landing day than before flight. Counseling of the crewmembers has resulted in postflight urine volumes averaging $21 /$ day. Additional evidence provided by the current study relative to the positive effects of increased urine volume can be seen in the two crewmembers who had urinary outputs $>2.5$ 1/day. These subjects minimized their risk of renal stone formation both before flight and during their flight. Increasing fluid intake and thus urine volume has been shown to bring urinary risk factors under the upper limit of metastability for solubility of stone-forming salts without effecting urinary stone inhibitor concentrations [16]. While recommendations to increase fluid intake can be made upon the crewmembers, it may not be feasible to implement as a crew medical requirement. Crewmember compliance is complicated as the result of work loads, schedules, extravehicular activities (EVAs) and the inconvenience of frequent urination in a microgravity environment.

Dietary factors, other than fluid intake, also play a key role in the development of renal stones [17-18]. High-protein diets are known to increase urinary calcium and uric acid and decrease urinary citrate. Oxalate from dietary sources may be even more lithogenic than dietary calcium, especially under conditions of calcium restriction. Reducing calcium intake enhances oxalate absorption by the gastrointestinal tract, which increases calcium oxalate supersaturation. Dietary sodium also may pose risks for 
hypercalciuria; high sodium intake leads to increases in urinary sodium and calcium, which elevates the risk of sodium urate and calcium-containing stones [19-20].

Dietary data from the long duration crewmembers studied in this investigation have proven to be difficult to evaluate. There were both astronauts and cosmonauts participating in this study. Some preflight assessments were performed in the United States, others in Russia. The diets of these two groups and two cultures vary significantly, including the in-flight foods prepared for these missions. However, some basic assumptions can be drawn from the data. There was a trend for dietary intake to be lower during flight as compared to the preflight period. For dietary oxalate, lower ingestion may have proved beneficial in reducing the risk of calcium stone formation by decreasing the urinary load of oxalate. However, decreased calcium intake will have a negative influence on bone deposition due to enhanced bone resorption in microgravity. Additionally, the trend toward lower total caloric intake will lead to weight loss among the crewmembers, an experience already observed among most crewmembers during and immediately after landing. Since the crewmembers in this study fell below dietary recommendations established by NASA, an increase in dietary calcium, sodium and protein intake may prove both advantageous to some medical issues but may be harmful in other ways as a result of the potential increased urinary load and their impact on renal stone formation. Selection of foods that are high in magnesium and potassium generally indicate an increased alkali dietary load. Several studies have linked an alkali diet with increased urinary citrate excretion $[6,21]$. The increased urinary citrate levels may decrease the risk of calcium stone formation by complexing with the urinary calcium and reducing the nucleation of urinary crystals. Overall, dietary selection may prove useful in reducing the risk of renal stone formation.
The International Space Station will open new areas for biomedical research in space. Living and working in microgravity creates demands on human physiology. A better understanding of these changes will lead to potential means to minimize the deleterious health effects on humans and optimize the human experience in space. The formation of a renal stone not only endangers the health and safety of the crewmember but also imperils the success of the mission. NASA is actively exploring methods to minimize these health risks. Increased fluid intake is already recommended to all crewmembers. Pharmacologic agents, such as potassium citrate, to reduce the risk of urinary crystallization and aggregation will be tested on future missions. The investigation of the effects of space flight on urinary protein inhibitors is underway. Currently, it is not possible to accurately predict how an individual will react physiologically to the microgravity environment or which crewmember may eventually develop a renal stone. A renal stone screening program to evaluate the urinary chemistry and recommend dietary changes or the use of in-flight countermeasures will help to ensure the health and safety of humans in space

\section{Acknowledgments}

The authors appreciate the assistance of the JSC Clinical Laboratories in analyzing the urine chemistry, German S. Arzamazov, M.D. and the staff at the Gagarin Cosmonaut Training Center for support during the data collection, and Ms Barbara L. Rice of Wyle Life Sciences for dietary analyses. We also thank Dr. Charles Y.C. Pak from the University of Texas Health Sciences Center for evaluation of the relative urinary supersaturation data and all the astronauts and cosmonauts who made this study possible.

This study was funded by the National Aeronautics and Space Administration (111-30-10-11).

\section{References}

1 Nicogossian AE: Overall physiological response to space flight; in Nicogossian AE, Huntoon CL, Pool SL (eds): Space Physiology and Medicine, ed 2. Philadelphia, Lea \& Febiger, 1989, chapt 7, p 139.

2 Whedon D, Lutwak L, Rambaut PC, Whittle M, Smith MW, Reid J, Leach CS, Stadler CR, Stanford DD: Mineral and nitrogen metabolic studies, experiment M071; in Johnston RS, Dietlein LF (eds): Biomedical Results from Skylab. NASA SP-377. Washington, DC, Na-

Renal Stones and Long Duration Space Flight tional Aeronautics and Space Administration, 1977 chapt 18, p 164.

3 Grigorev AI, Dorokhova BP, Semenov VIu, Morukov BM, Baichorov EO: Water-electrolyte balance and functional state of kidneys in cosmonauts after a 185-day space flight. Kosm Biol Aviakosm Med 1985;19:21-27.

4 Grigoriev AI, Morukov BV, Vorobiev DV: Water and electrolyte balance during long-term missions onboard the space stations Salyut and Mir. Clin Invest 1994;72:169-189.
5 Grigoriev AI, Egorov AD: The effects of prolonged space flights on the human body. Adv Space Biol Med 1991;1:1-35.

6 Whitson PA, Pietrzyk RA, Pak CYC, Cintron NM: Alterations in renal stone risk factors after space flight. J Urol 1993;150:803-807.

7 Arzamazov GS, Whitson PA, Larina ON, Paastshkova LKh, Pak CYC: Assessment of risk factors for urolithiasis in cosmonauts during long flights. Aviakosm Ekolog Med 1996; 30:24-32. 
8 Whitson PA, Pietrzyk RA, Pak CYC, Cintron NM: Renal stone risk assessment during space shuttle flights. J Urol 1997;158:2305-2310.

9 Nicar JN, Hsu MC, Johnson T, Pak CYC: The Preservation of Urine Samples for the Determination of Renal Stone Risk Factors. Lab Med 1987;18:382.

10 Finlayson B: Calcium stones: Some physical and clinical aspects; in David DS (ed): Calcium Metabolism in Renal Failure and Nephrolithiasis. New York, Wiley \& Sons, 1977, p 337.

11 Lane HW, Smith SM: Nutrition in Space; in Shils ME, Olson JA, Shike M, Ross AC (eds): Modern Nutrition in Health and Disease. Baltimore, Williams \& Wilkins, 1999, chapt 48, pp 783-788.

12 Oh MS: A new method for estimating G-I absorption of alkali. Kidney Int 1989;36:915917.
13 Messa P, Mioni G, Paganin L, Cruciatti A, LoGreco P, Turrin D: Urinary citrate, bone resorption and intestinal alkali absorption in stone formers with fasting hypercalciuria. Scan Microsc 1994;8:531-538.

14 Nicogossian AE, Pool SL, Uri JJ: Historical perspectives; in Nicogossian AE, Huntoon CL, Pool SL (eds): Space Physiology and Medicine, ed 3. Edited by Philadelphia, Lea \& Febiger, 1994, chapt 1, pp 3-49.

15 Whedon D, Lutwak L, Rambaut PC, Whittle M, Leach CS, Reid J, Smith M: Effects of weightlessness on mineral metabolism: Metabolic studies on Skylab orbital space flights. Calcif Tissue Res 1976;21:423-430.

16 Pak CYC, Sakhaee K, Crowther C, Brinkly L: Evidence justifying a high fluid intake in treatment of nephrolithiasis. Ann Intern Med 1980; 93:36-39.
17 Curhan GC, Curhan SG: Dietary factors and kidney stone formation. Compr Ther 1994;20: 485-489.

18 Brown WW and Wolfson M: Diet as culprit or therapy. Clin Nutr 1993;77:783-794.

19 Hill JM, Harvey PW, Fleming SJ: Dietary treatment of idiopathic urolithiasis. Med J Aust 1993;159:366-367.

20 Massey LK, Whiting SJ: Dietary salt, urinary calcium and kidney stone risk. Nutr Rev 1995; 53:131-139.

21 Pak CYC: Citrate and renal calculi: New insights and future directions. Am J Kidney Dis 1991;17:420-425. 